\title{
From ESPN to Instagram LIVE: The Evolution of Fan-Athlete Interaction Amid the Coronavirus
}

\author{
Lillian Feder \\ University of California San Diego
}

\begin{abstract}
With sporting events canceled and Safer at Home orders in place, both athletes and sports fans have a void to fill. Consequently, social media use by both parties has increased. Athletes have become more active and interactive online, which may serve to strengthen parasocial relationships between them and their fans. These connections could develop to the extent that the line between parasocial relationship and friendship is blurred. Will stronger ties between athletes and fans be a by-product of COVID-19? In this editorial, the author builds an argument for the plausibility of this result by linking published studies regarding sports fandom and parasocial relationships to current trends in athletes' use of social media. The author then raises questions regarding the future of sports fandom, which can be assessed once athletics resume. To conclude, the author offers practical recommendations to sports organizations coming out of COVID-19-related suspensions.
\end{abstract}

Keywords: parasocial relationships, professional athletes, social media

How many times have you left your house in the last month? What have you found to do instead? While quarantined, many professional athletes have found themselves engaging with social media more regularly than before (Baker, 2020). This bodes well for fans' parasocial relationships with them, as these strong onesided connections "arise when individuals are repeatedly exposed to a media persona, and the individuals develop a sense of intimacy, perceived friendship, and identification with the [athlete]" (Chung \& Cho, 2017, p. 482). This variety of exposure has been made available to fans by professional athletes who have regularly used social media platforms and features such as TikTok and Instagram LIVE from their homes.

In an effort to keep himself and his fans entertained and engaged with positive content while quarantined, National Basketball Association (NBA) star Serge Ibaka has created an Instagram LIVE talent competition called How Talented Are You? Episodes mimic a mediated version of American Idol-style auditions, with Ibaka and special guests serving as judges while fans who have been selected to compete display their talents. Special guests have included NBA stars DeMar 
DeRozan and Pau Gasol as well as actresses Tiffany Haddish and Keke Palmer. The competition provides a platform not only for entertainment but also for open and immediate two-way interaction between high-profile celebrities and fans on a consistent basis. Birthed in reaction to the impact of the COVID-19 pandemic, How Talented Are You? is exemplary in its display of the pandemic's role in changing the relationship between professional athletes and their fans.

How Talented Are You? did so well upon release that the account crashed during the first episode. The same motivating factor that drove Ibaka to run the live talent show on social media is what pushed fans to tune in to the live stream the day it aired. That source of motivation is the coronavirus. Quarantine breeds isolation and, in turn, intensifies individuals' longing for social interaction. With a universal impact affecting both professional athletes and their fans, quarantine also provides a point of connection for the two otherwise distinct groups through shared experience. While quarantined, athletes and fans have taken advantage of this opportunity to connect in a different, more direct way by interacting with one another more regularly than they otherwise would on social media. Heightened online interaction between professional athletes and fans has served to strengthen their existing parasocial relationships. The more consistent and personal these interactions become, the more likely it is that fans will begin to consider their relationships with professional athletes as two-way rather than one-sided. Furthermore, the more individuals rely on online interaction to connect them to their friends and family, the more similar fans' interactions with friends, family, and professional athletes can become.

\section{Craving Content and Connection While Quarantined}

With less to do and virtually nowhere to go, individuals are becoming increasingly hungry for online content and connection (Hutchinson, 2020; Kantar, 2020; Schultz, 2020). Mediated communication has become the only option for those looking to keep in touch with their friends and family. Thus, staying connected online is no longer simply supplemental to face-to-face interaction in building and maintaining interpersonal relationships. Uses and gratifications literature deems social interaction and entertainment two primary sources of motivation driving individuals to log on to social networking sites (Brandtzæg \& Heim, 2009; Eginli \& Tas, 2018; Papacharissi \& Rubin, 2000; Raacke \& Bonds-Raacke, 2008). External fulfillment of both of these motivators is depleted by the reality of the COVID-19 pandemic, further amplifying the value of social media in fulfilling these human needs.

In a content-filled, consumer-driven society, entertainment is often delivered without being sought out. However, in the midst of the COVID-19 pandemic, fewer options for external amusement are readily available. Consequently, individuals must seek out entertainment for themselves, and, in turn, social media use is likely to surge. With television shows unable to continue filming and new content coming from traditional forms of media running out, social media, as a source of entertainment, has less competition than usual. As a result, the demand for user-generated content is rapidly increasing. This has rendered a majority of individuals across the globe eager to produce and consume a higher volume of 
social media posts regardless of status or profession (Hutchinson, 2020; Kantar, 2020; Schultz, 2020).

\section{Fan-Athlete Interaction via Social Media}

Much like their fans, professional athletes have historically used social media for social interaction and entertainment purposes (Hambrick, Simmons, Greenhalgh, \& Greenwell, 2010). Unlike their fans, however, a number of professional athletes amass enormous online followings almost immediately after publishing their social media profiles regardless of the content or frequency of their posts (Vergeer \& Mudler, 2019; Ye, Fang, He, \& Hsieh, 2012). Many professional athletes publish posts to their social media profiles more frequently during offseason than they do when they are competing as a means of maintaining a connection with their fans. With every athletic season currently at a standstill, all athletes are in their offseason. Thus, the reality of the COVID-19 pandemic has driven many athletes to publish posts to their social media profiles more frequently than they did before the virus hit (Baker, 2020). In turn, the pandemic may be responsible for the heightened exposure of sports fans to varying facets of the athletes whom they admire.

Evidently, as the COVID-19 pandemic drives social media engagement for both professional athletes and their fans, there is a greater potential for various forms of online interactivity between the two groups. In addition to posting more content to their profiles, with more free time and a greater need to seek out entertainment and validation for themselves, professional athletes may be inclined to like, comment on, and repost other users' posts more frequently than ever before. Furthermore, with more free time, professional athletes are likely to experiment with applications and application features they had yet to delve into, thereby diversifying and personalizing the delivery of the content they post. For example, NBA stars Stephen Curry, Serge Ibaka, JaVale McGee, Chris Paul, and Carmelo Anthony, alongside National Football League (NFL) star Emmanuel Sanders, have become regulars on Instagram LIVE. Similarly, NBA stars LeBron James, Jordan Clarkson, and Bradley Beal, as well as NFL star Jarvis Landry, have become active on TikTok.

In terms of their more general social media habits, professional athletes are more inclined to post personally charged rather than athletically charged content online during their offseason. Moreover, with seasons suspended and Safer at Home orders in place, professional athletes' arsenal of athletically charged content is depleted. Thus, it is likely that professional athletes will continue to post a higher volume of almost exclusively personally charged content to their social media profiles in the coming weeks. In addition, many professional athletes are currently in the same situation as their fans in terms of their need to be resourceful when attempting to stay connected, entertained, and active at home. In this way, the COVID-19 pandemic has humanized professional athletes, making them more relatable to their fans.

\section{Athletes' Quarantine-Inspired Posts}

Rather than publishing posts centered around how many points they scored in their most recent competition or how excited they are to compete in their next matchup, 
professional athletes are currently publicizing their more intimate thoughts, feelings, and behaviors. While quarantined, Chris Paul and Carmelo Anthony connected via Instagram LIVE to catch up and engage with their fans. After briefly discussing how they have been spending their time at home, the pair began to address questions asked by their fans in real time. When asked what advice he had to offer young athletes who were unable to finish their high school and college seasons, Anthony took the opportunity to draw a parallel between that predicament and his own. Recognizing the unsettling nature of uncertainty and pointing out his own discomfort, Anthony emphasized the importance of "staying locked in" as he urged young athletes to keep busy, avoid dwelling on negativity, and "take it day by day" (Paul, 2020).

Similarly, Stephen Curry has frequently used the Instagram LIVE feature to engage in conversations with other professional athletes that would have otherwise remained private. Many of these conversations have offered the athletes' insights regarding the impact of the pandemic on themselves, their social circles, the industry of professional athletics, and the outside world. In these conversations, it is apparent that the main worries of professional athletes-health, safety, stability, and so onare currently more closely aligned with the general worries of their fans.

Also, these conversations involve a back and forth on how professional athletes, as isolated individuals, are keeping themselves occupied while quarantined. Bradley Beal, JaVale McGee, LeBron James, and Jarvis Landry have used Instagram LIVE, TikTok, and Instagram's story feature to publish posts of themselves dancing and otherwise playfully engaging with their families regularly over the last month. In the meantime, Jordan Clarkson has revealed another side to himself by keeping up with TikTok trends and publishing his own variations of many viral dances and skits.

\section{The Humanization of Athletes via Social Media}

As professional athletes continue to open up and display more dimensions of their lives on social media, fans are able to see more of the full picture of the athletes they admire as complete human beings. Rather than viewing Bradley Beal exclusively as an NBA standout with an impressive athletic orientation, fans are able to see Bradley Beal as an NBA standout, a father, a husband, and an individual who is currently trying to make the most of quarantine. Similarly, fans have been exposed to another side of Stephen Curry, as he has been outspoken about his current role as a substitute teacher for his young children. The relatable nature of the content currently being posted online by professional athletes expands the potential for new fans of these athletes to form parasocial relationships with them without watching them compete. Furthermore, the dissemination of this kind of content expands the opportunity for depth in identification among fans who have already formed parasocial relationships with the athletes they admire.

Fans who view the athletes they admire as multifaceted and relatable individuals experience deeper and more meaningful parasocial relationships (Feder, 2019). This level of connection often leads to the development of an affective bond on the part of the fan, indicating a higher level of engagement and attachment to the athlete (Pan \& Zeng, 2018). With a one-to-many delivery style 
that is often consumed similarly to a one-to-one asynchronous connection, social media empowers fans to more strongly identify with the athletes they admire (Chung \& Cho, 2017; Feder, 2019), especially when exposed to personally charged content while quarantined. In the absence of face-to-face social interaction, fans' mediated interactions with athletes become increasingly similar to their everyday interactions with friends. This, in addition to the greater likelihood for athletes to post personally charged rather than athletically charged content on their profiles while quarantined, may serve to strengthen the relationship between athletes and fans to the extent that the relationship is no longer completely one-sided.

As Safer at Home orders remain in place and professional athletes continue to post personally charged content to their social media profiles, the line between parasocial relationship and friendship is likely to blur for their fans. The potential for this effect could be amplified if a particular athlete who is not known to have a consistent presence on social media begins to post, repost, like, and comment consistently. With greater levels of identification to the athletes they admire, particularly to the extent that an online friendship is formed, fans may develop new expectations with respect to their evolving relationships with these athletes. Considering that these expectations would be formed in the absence of competition-when athletes have significantly more free time and fans have less of an opportunity to experience vicarious achievement through athletes' accomplishments-fans may be setting themselves up for a letdown once competition resumes.

\section{Future Directions and Practical Implications}

It is impossible to state the trajectory of the COVID-19 pandemic's impact on the sports industry in the current moment. However, social distancing is certain to alter fans' association to the world of sport and the athletes who they admire. Future research should examine the effects of the pandemic on fans' orientation to professional sports by examining the strength of the ties between sports fans and the athletes and teams that they admire as athletics resume. In the event that stronger ties between athletes and fans are found to be a by-product of the COVID19 pandemic, researchers should assess fans' newly formed expectations considering their evolved relationships with the athletes who they admire. If there is a drop in online interaction between athletes and fans once competition resumes, fans may feel betrayed or gain a heightened awareness of the one-sided nature of their relationships with the athletes whom they admire. This could, in turn, affect fans' support of the athletes who have let them down, which may lead to a parallel result for the teams those athletes are associated with. However, resumed competition and vicarious achievement may overcome this potential burden and serve to maintain high levels of identification among fans regardless of athletes' online presence. Either way, the future of sports fandom is certain to be shaped in large part by the implications of this period of athletic inactivity.

As athletics resume and we begin organizational reintegration, professional athletes and front offices will be wise to maintain a strong orientation toward the social interaction and entertainment-based needs of their fans. In addition to humanizing professional athletes, quarantine grants professional athletes and front office employees the opportunity to better understand and identify with sports fans. 
As they are placed in similar predicaments and navigating similar challenges to sports fans, the shared experience of being quarantined should empower professional athletes and front office employees to better position their brands once athletics resume. In addition, current trends in fan-athlete online interaction provide professional athletes with valuable insights with respect to fans' preferred fan-athlete dynamic. These insights should be used to guide professional athletes as they frame future social media posts and interactions with their fans to ensure fans' needs continue to be met once competition resumes.

It is highly likely that resumed competition will result in reduced fan-athlete online interaction. As athletes return their focus to competition, they will have less time to dedicate to engaging with their fans on social media. As a result, fan-athlete interaction is likely to regress, trending more closely to a one-way dynamic once again initiated and maintained primarily by fans. In order to avoid the deterioration of parasocial relationships resulting in fans' loss of interest and support for the athletes who they admire, professional athletes must use the insights gained during quarantine to deliver high-quality content to their fans once competition resumes. This content should serve to replenish fan-athlete connection in compensation for the inevitable shift in athletes' use of social media.

\section{References}

Baker, K. (2020). Bored athletes take to Instagram to connect with fans during coronavirus shutdown. Axios. Retrieved from https://www.axios.com/instagram-athletescoronavirus-streaming-e098236c-095b-4996-b596-15d099a662dc.html

Brandtzæg, P., \& Heim, J. (2009). Why people use social networking sites. In A.A. Ozok, \& P. Zaphiris (Eds.), Lecture Notes in Computer Science (Vol. 5621, pp. 143-152). Berlin, Heidelberg: Springer. doi:10.1007/978-3-642-02774-1_16

Chung, S., \& Cho, H. (2017). Fostering parasocial relationships with celebrities on social media: Implications for celebrity endorsement. Psychology \& Marketing, 34(4), 481-495.

Eginli, A., \& Tas, N. (2018). Interpersonal communication in social networking sites: An investigation in the framework of uses and gratification theory. Online Journal of Communication and Media Technologies, 8(2), 81-104.

Feder, L. (2019). Athlete activism online: An examination of subsequent fan engagement (Unpublished master's thesis). West Lafayette, IN: Purdue University. Retrieved from https://doi.org/10.25394/PGS.8006078.v1

Hambrick, M.E., Simmons, J.M., Greenhalgh, G.P., \& Greenwell, T. (2010). Understanding professional athletes' use of Twitter: A content analysis of athlete Tweets. International Journal of Sport Communication, 3(1), 454-471. doi:10.1123/ijsc.3.4.454.

Hutchinson, A. (2020). Twitter says user numbers are up amid COVID-19 lockdowns, but warns of revenue impacts. Social Media Today. Retrieved from https://www.social mediatoday.com/news/twitter-says-user-numbers-are-up-amid-covid-19-lockdowns-butwarns-of-reve/574719/

Kantar. (2020). COVID-19 barometer: Consumer attitudes, media habits and expectations. Kantar Media. Retrieved from https://www.kantar.com/Inspiration/Coronavirus/ COVID-19-Barometer-Consumer-attitudes-media-habits-and-expectations

Pan, P.-L., \& Zeng, L. (2018). Parasocial interactions with basketball athletes of color in online mediated sports. Howard Journal of Communications, 29(2), 196-215. doi:10. 1080/10646175.2017.1354790 
Papacharissi, Z., \& Rubin, A. (2000). Predictors of internet use. Journal of Broadcasting \& Electronic Media, 44(2), 175-196. doi:10.1207/s15506878jobem4402_2

Paul, C. [@cp3]. (2020). LIVE [Instagram profile]. Retrieved from https://instagram.com/ cp3?igshid=13a5di1q6jzio

Raacke, J., \& Bonds-Raacke, J. (2008). MySpace and Facebook: Applying the uses and gratifications theory to exploring friend-networking sites. Cyber Psychology \& Behavior, 11(2), 169-174. doi:10.1089/cpb.2007.0056

Schultz, A. (2020). Keeping our services stable and reliable during the COVID-19 outbreak. Facebook. Retrieved from https://about.fb.com/news/2020/03/keeping-our-appsstable-during-covid-19/

Vergeer, M., \& Mudler, L. (2019). Football players' popularity on Twitter explained: Performance on the pitch or performance on Twitter? International Journal of Sport Communication, 12(3), 376-396. doi:10.1123/ijsc.2018-0171

Ye, Q., Fang, B., He, W.J., \& Hsieh, J.J. (2012). Can social capital be transferred cross the boundary of the real and virtual worlds? An empirical investigation of Twitter. Journal of Electronic Commerce Research, 13(2), 145-156. 